\title{
Median-Unbiased Estimation in DF-GLS Regressions and the PPP Puzzle
}

\author{
Claude Lopez $^{a} \quad$ Christian J. Murray ${ }^{b} \quad$ David H. Papell $^{b}$ \\ ${ }^{a}$ University of Cincinnati, ${ }^{b}$ University of Houston
}

May 2008

\begin{abstract}
Using median-unbiased estimation, recent research has questioned the validity of Rogoff's "remarkable consensus" of 3-5 year half-lives of deviations from PPP. These half-life estimates, however, are based on estimates from regressions where the resulting unit root test has low power. We extend median-unbiased estimation to the DF-GLS regression of Elliott, Rothenberg, and Stock (1996). We find that median-unbiased estimation based on this regression has the potential to tighten confidence intervals for half-lives. Using long horizon real exchange rate data, we find that the typical lower bound of the confidence intervals for median-unbiased half-lives is just under 3 years. Thus, while previous confidence intervals for half-lives are consistent with virtually anything, our tighter confidence intervals now rule out economic models with nominal rigidities as candidates for explaining the observed behavior of real exchange rates. Therefore, while we obtain more information using efficient unit root tests on longer term data, this information moves us away from solving the PPP puzzle.
\end{abstract}

\section{Correspondence:}

Claude Lopez, Department of Economics, University of Cincinnati tel: (513) 556 2346, fax: (513) 5562669 email: claude.lopez@uc.edu

Chris Murray, Department of Economics, University of Houston tel: (713) 743 3835, fax: (713) 743 3798, email: cmurray@mail.uh.edu

David Papell, Department of Economics, University of Houston tel: (713) 743 3807, fax: (713) 743 3798, email: dpapell@mail.uh.edu

We thank Lutz Kilian, Barbara Rossi, seminar participants at Duke University, Texas Econometrics Camp 8, the Southern Economic Association meetings, and two anonymous referees for helpful comments and discussions. Papell thanks the National Science Foundation for financial support. 


\section{Introduction}

During the past decade, a number of studies using long-horizon data have changed the focus of research on Purchasing Power Parity (PPP) from the narrow question of whether or not the real exchange rate contains a unit root to the broader question of the persistence of deviations from PPP. Abuaf and Jorion (1990), Diebold, Husted and Rush (1991), Glen (1992), Cheung and Lai (1994), and Lothian and Taylor (1996) all reach the same conclusion: the hypothesis of a unit root in real exchange rates can be rejected and the half-life of the PPP deviations varies between 3 and 5 years. ${ }^{1}$ In his well-known survey, Rogoff (1996) discusses the "remarkable consensus" of these half-lives and coins the phrase "purchasing power parity puzzle" to describe the difficulty in reconciling these slow speeds of adjustment with the high short-run volatility of real exchange rates. The slow speed of adjustment is problematic for models with nominal rigidities which predict faster convergence to PPP of 1 to 2 year half-lives.

Although the 3 to 5 year consensus has become the common starting point in attempts to "solve" the PPP puzzle, the consensus itself is problematic. The studies cited above generally calculate least squares point estimates of the half-lives from first order autoregressive processes. Point estimates alone do not provide a complete measure of persistence. Cheung and Lai (2000) supplement point estimates with conventional bootstrap confidence intervals in order to measure the precision of the half-life estimates. Their confidence intervals, however, are not valid under the unit root null and, even if long run PPP holds, are biased downwards in small samples. ${ }^{2}$ In addition, the least squares estimates of half-lives are biased downward, providing an inaccurate picture of the speed of adjustment to PPP.

Two recent papers address these issues using classical estimation techniques. ${ }^{3}$ Murray and Papell (2002) use the median-unbiased estimation methods of Andrews (1993) and the approximately median-unbiased methods of Andrews and Chen (1994) for Dickey-Fuller (DF) and Augmented Dickey-Fuller (ADF) regressions respectively. They calculate point estimates and confidence intervals for half-lives of PPP deviations for

\footnotetext{
${ }^{1}$ Engel (2000) raises the question of whether these rejections are caused by size distortions.

${ }^{2}$ See Kilian (1998), Hansen (1999), Kilian (1999), and Inoue and Kilian (2002) for further discussion of bootstrapping autoregressive processes with unit roots or near unit roots.

${ }^{3}$ See Kilian and Zha (2002) for a Bayesian perspective.
} 
post-1973 quarterly US dollar real exchange rate data for 20 countries. Rossi (2005) uses the confidence interval estimation methods of Elliott and Stock (2001) and Hansen (1999) to calculate bias-corrected confidence intervals for half-lives of PPP deviations for 17 floating real exchange rates. Despite the differences in methodology, the results the two papers are nearly identical. The lower bounds of the $95 \%$ confidence intervals are mostly just above one year, while the upper bounds are generally infinite. These results, however, do not help "solve" the PPP puzzle. While the lower bounds are consistent with relatively fast convergence to PPP as predicted by models with nominal rigidities, the upper bounds are consistent with a unit root in real exchange rates and no convergence to PPP even in the very long run. ${ }^{4}$

These results indicate that univariate methods are unlikely to be informative about the persistence of post-1973 real exchange rates. ${ }^{5}$ Focusing on post-1973 rates, moreover, ignores most of the available data. While long-horizon data mixes fixed and flexible nominal exchange rate regimes and, therefore, cannot answer the question of whether PPP would hold with a century long flexible nominal exchange rate regime, it can potentially answer the question of whether PPP has held over the last century.

This potential has been greatly facilitated by the work of Taylor (2002), who develops real exchange rate data for over 100 years for 20 countries. An important contribution of Taylor's work is that, for the first time, it is possible to investigate real exchange rate persistence using long-horizon data with approximately the same set of advanced countries as is commonly used in studies with post-1973 data.

The purpose of this paper is to improve inference on the persistence of PPP deviations in long-horizon real exchange rates. We extend the methodology developed by Andrews (1993) and Andrews and Chen (1994) for Dickey-Fuller and Augmented Dickey-Fuller regressions, respectively, to the DF-GLS regression corresponding to the more powerful unit root test of Elliott, Rothenberg, and Stock (1996). We compute median-unbiased

\footnotetext{
${ }^{4}$ Taylor (2001) and Imbs et al. (2005) investigate time aggregation and sectoral heterogeneity bias, respectively, although their results remain controversial. We treat the measured real exchange rate as the object of interest, and thus do not consider these potential sources of bias.

${ }^{5}$ Panel methods have been used extensively to test for unit roots in post-1973 real exchange rates. Murray and Papell (2005) and Mark, Choi and Sul (2005) examine real exchange rate persistence with panel methods. Elliott and Pesavento (2006) use univariate unit root tests with stationary covariates to investigate PPP in post 1973 data. These covariate augmented unit root tests have not yet been extended to calculate unbiased half-life estimates.
} 
and approximately median-unbiased point estimates and confidence intervals for halflives of PPP deviations for DF-GLS regressions. We use Taylor's (2002) data for 9 annual US dollar real exchange rates for developed countries with over a century of data for each country. To our knowledge, this is the first paper which corrects for median-bias in DF-GLS regressions.

Andrews (1993) shows how to calculate median-unbiased point estimates and confidence intervals for half-lives in DF regressions, and tabulates the bias for a range of parameter values and sample sizes. We conduct a similar tabulation for DF-GLS regressions. We find that, while the estimates from DF-GLS regressions are biased downwards, the extent of the bias is much less than in Dickey-Fuller regressions. In addition, the confidence intervals for median-unbiased estimators are tighter for DF-GLS regressions than for $\mathrm{ADF}$ regressions. This demonstrates the potential for sharper inference on the persistence of shocks to the real exchange rate than has been previously available.

We proceed to calculate median-unbiased point estimates and confidence intervals for half-lives of PPP deviations for the 9 long-horizon real exchange rates. The point estimates of the half-lives are considerably larger than would be expected based on Rogoff's 3-5 year "consensus". The median value (among the 9 rates) based on the DFGLS regression is 7.46 years, with a median $95 \%$ confidence interval of $[2.86,21.24]$ years.

The major result in both Murray and Papell (2002) and Rossi (2005) is that for quarterly post 1973 real exchange rates, the confidence intervals of the half lives were so wide as to be consistent with virtually anything. ${ }^{6}$ We find a very different result here. The median lower bound of our $95 \%$ confidence intervals is just under 3 years. Since the half-lives that would be predicted from models with nominal rigidities are generally 1 to 2 years, our results are clearly inconsistent with the predictions from such models. Therefore, while we obtain greater information about the persistence of shocks to the real

\footnotetext{
${ }^{6}$ Murray and Papell (2002) also analyze 6 long horizon (1900-1996) real exchange rates, but the set of counties is non overlapping with the series used here, and they are constructed with WPIs rather than CPIs as in Taylor (2002).
} 
exchange rate, the PPP puzzle becomes even more problematic.

\section{Median-Unbiased Estimation in DF-GLS Regressions.}

Murray and Papell (2002) use the median-unbiased techniques of Andrews (1993) and Andrews and Chen (1994) to compute point estimates and confidence intervals for PPP half-lives. Since these estimates are based on ADF regressions, they do not optimally exploit the sample information in terms of power. We propose an extension of the Andrews (1993) and Andrews and Chen (1994) methodology to the DF-GLS regression. The objective here is to obtain tighter confidence intervals than those of Murray and Papell (2002) to potentially shed more light on the PPP puzzle. ${ }^{7}$

The extension of median-unbiased estimation to DF-GLS regressions is straightforward. Andrews' (1993) exactly median-unbiased estimator is based on DF regression

$$
q_{t}=c+\alpha q_{t-1}+u_{t},
$$

whereas the Andrews and Chen (1994) approximately median-unbiased estimator is based on the ADF regression

$$
q_{t}=c+\alpha q_{t-1}+\sum_{i=1}^{k} \psi_{i} \Delta q_{t-i}+u_{t},
$$

where $k$ lagged differences are included to account for serial correlation. ${ }^{8}$

Instead of working with the data in levels as in the ADF regressions, we simply work with the GLS demeaned (or detrended) data in the auxiliary DF-GLS regression

$$
q_{t}^{\mu}=\alpha q_{t-1}^{\mu}+\sum_{i=1}^{k} \psi_{i} \Delta q_{t-i}^{\mu}+u_{t}
$$

\footnotetext{
${ }^{7}$ We note that the DF-GLS test is not necessarily more powerful than the Dickey-Fuller test if the initial value of the series is far away from its potential long run mean; see Müller and Elliott (2003). For all of the real exchange rates we consider here, the initial value is close to the sample mean, so that there is no compelling reason to think that our methodology would not produce tighter confidence intervals than Andrews and Chen (1994). It is also the case that if the real exchange rates exhibit nonlinear mean reversion, then the DF-GLS test is not necessarily more powerful. We do not consider nonlinear reversion to long run PPP in this paper. Finally, if a time series is not very persistent, the DF-GLS test might not provide a gain in power over the ADF test. However, as we will see in the empirical section, our DF-GLS confidence intervals are tighter than their ADF counterparts when we control for lag selection.

8 The regression with only a constant and a lagged dependent variable is Case 2 in Andrews (1993). Cases 1 and 3 have no deterministic regressors, and a constant and time trend respectively. Since we are interested in the strict interpretation of PPP, for our purposes Case 2 is appropriate.
} 
where $q_{t}^{\mu}$ is the GLS demeaned real exchange rate. That is, $q_{t}^{\mu}=q_{t}-\widetilde{\beta} z_{t}$, where $z_{t}=1$, $\tilde{\beta}=\left(\sum \tilde{z}_{t}^{2}\right)^{-1} \sum \tilde{z}_{t} \tilde{q}_{t}, \quad \tilde{q}_{t}=\left(q_{1},\left(q_{2}-\alpha q_{1}\right), \ldots,\left(q_{T}-\alpha q_{T-1}\right)\right)^{\prime}, \quad \tilde{z}_{t}=(1,(1-\alpha), \ldots,(1-\alpha))^{\prime}$, $\alpha=1+c / T$, and $c=-7 .{ }^{9}$ Since deterministic terms have been removed by GLS demeaning, none are present in the above regression. ${ }^{10}$ When $k=0$, as in Andrews (1993), the median-unbiased estimator is exact, and when $k>0$, as in Andrews and Chen (1994), the median-unbiased estimator is approximate. ${ }^{11}$

\subsection{Exactly Median-Unbiased Estimation}

We compute our exactly median-unbiased estimator for equation (3) with $k=0$ for the sample sizes considered by Andrews (1993). We also report 90\% confidence intervals. Specifically, for each value of $\alpha$, we generate $10^{5} \mathrm{AR}(1)$ processes with iid Gaussian innovations. To find the median-unbiased estimator, we find the value of $\alpha$ such that the median of the least squares estimator is equal to the least squares estimate. For example, if the least squares estimate of $\alpha$ is 0.915 and $T+1=125$, the medianunbiased estimate of $\alpha$ based on the DF-GLS regression is 0.930. A similar exercise leads to the construction of confidence intervals. Our estimator is reported in the first row of Table 1, and Andrews' estimator, based on equation (1), is reported in the second row of Table $1 .{ }^{12}$

The median-unbiased estimator of $\alpha$ in the $\operatorname{AR}(1)$ case is only exact if the distribution of the innovations is correctly specified. If the errors are non Gaussian, which they are likely to be in most economic time series, then the above procedure will not produce exactly median-unbiased estimates. However, Andrews (1993) demonstrates that the median-unbiased estimator is quite robust to departures from Normality. Specifically, if the error terms are skewed and kurtotic, but have finite variance, then the approximation error resulting from incorrectly assuming Gaussian errors is quite small.

\footnotetext{
9 We note that the $\alpha$ s in equations (2) and (3) are in general not the same, but we use the same notation for convenience.

${ }^{10}$ Again, since we are interested in the strict interpretation of PPP, we do not allow for deterministic time trends, although doing so is straightforward.

11 See Andrews and Chen (1994) and Murray and Papell (2002) for further details concerning the computation of approximately median-unbiased estimators.
} 
Two features of Table 1 are important to highlight here. First, while median-bias is present in the least squares estimator of $\alpha$ in DF-GLS regressions, it is not as severe as the bias in ADF regressions. This accords with intuition since bias worsens as the number of deterministic regressors increases. The auxiliary DF-GLS regression contains no deterministic terms, while the ADF regression contains a constant. Second, the confidence intervals from the DF-GLS regressions are tighter than from the ADF regressions. Uniformly, the lower bounds of the confidence intervals for the medianunbiased estimator of $\alpha$ are higher in the DF-GLS regressions than in the ADF regressions. Similarly, with only a few exceptions when $T+1=40$, the upper bounds from the DF-GLS regressions are higher than from the ADF regressions. Even though both the upper are lower bounds are higher, the confidence intervals are uniformly tighter in the DF-GLS case. This derives from the greater power of the DF-GLS test, and demonstrates the potential to extract more information on the persistence of shocks to real exchange rates than has been previously available.

\subsection{Approximately Median-Unbiased Estimation}

When $k>0$, even if the distribution of the innovations is correctly specified, the median-unbiased estimator is no longer exact, but approximate. In addition, the half-life, which is based on the impulse response function, is a nonlinear transformation of an approximately median-unbiased estimate, and is therefore biased. In this subsection, we conduct a simulation study of the half-life estimate to determine how our proposed halflife estimator performs relative to that of Andrews and Chen (1994), in terms of bias and precision.

We consider four values of $\alpha: 0.85,0.90,0.95$, and 1 . For each value of $\alpha$, we generate multiple parameterizations, either $2^{\text {nd }}$ or $3^{\text {rd }}$ order autoregressions. The true halflives of all the parameterizations we consider range from 3.3 years to infinity. For each parameterization, we generate $10^{5}$ artificial AR processes with iid Gaussian innovations and compute the approximately median-unbiased estimate of the half-life, as well as the 95\% confidence interval, using our proposed methodology, as well as that of Andrews

\footnotetext{
${ }^{12}$ While our subsequent empirical application reports $95 \%$ confidence intervals, we report $90 \%$ confidence intervals in Table 1 in order to directly compare our estimator to Andrews' estimator, for which he does not
} 
and Chen (1994). The half-life is computed directly from the impulse response function, and is defined as the number of periods required for the impulse response function to fall permanently below one half. In the simulations, the value of $k$ is set to its true value at each iteration, although in practice it would have to be estimated. The results are reported in Table 2.

There are two main features of Table 2 worth noting. First, although not severe, our estimate of the half-life is downward biased for every data generating process we consider. In addition, the bias we find in our estimator is greater than the bias of the Andrews and Chen (1994) estimator. While our estimator is arguably outperformed by the Andrews and Chen estimator in terms of point estimates of the half-life, it paints a more precise picture of the persistence of shocks to the real exchange rate. Our $95 \%$ confidence intervals are tighter in every case. Our lower bounds of the half-life are always higher, and except for the case where the true half-life is infinity, our upper bounds are always lower. The confidence interval of the half-life is arguably more important than the point estimate when one is trying to compare the persistence of shocks to the exchange rate with the predictions from economic models. ${ }^{13}$ Our proposed methodology leads to notably tighter confidence intervals than those computed from the Andrews and Chen (1994) methodology, and demonstrates the ability to gain more information regarding the PPP puzzle when the median-unbiased estimator is only approximate.

\section{Empirical Results: The Persistence of Shocks to the Real Exchange Rate}

Taylor (2002) collects nominal exchange rate and price level data through 1996 for 20 countries, each for over 100 years, yielding 19 US dollar denominated real exchange rates. The price levels are consumer price deflators or, if not available, GDP deflators. We extend Taylor's data through 1998, and omit Argentina, Brazil, and Mexico, in order to focus solely on developed countries. This leaves us with 16 dollar denominated real exchange rates: Australia, Belgium, Canada, Denmark, Finland, France, Germany, Italy, Japan, the Netherlands, Norway, Portugal, Spain, Sweden, Switzerland, and the United

report $95 \%$ confidence intervals.

${ }^{13}$ Using a different methodology, Rossi (2005) only reports confidence intervals for half-lives. 
Kingdom. The data begin as early as 1870, and exact starting dates for each real exchange rate are provided in Table 3.

Before we compute half-lives, we must first address the issue of structural change. It is quite possible, even likely, that a more than century long real exchange rate spanning many different nominal exchange rate regimes will exhibit structural change. Furthermore, the relationship between structural change and the median-bias of least squares estimates of $\alpha$ is not yet fully understood. So that we can focus only on persistence, rather than persistence in the presence of structural change, we only estimate half-lives for those real exchange rates where there is evidence that structural breaks do not occur.

Perron (1989) and Papell and Prodan (2007) provide analytical and simulation based evidence respectively that the presence of structural change lowers the power of tests for a unit root when structural change is ignored. We use this result to determine which of our 16 real exchange rates can be analyzed without having to account for structural breaks. Specifically, if the null hypothesis of a unit root is rejected with a DF-GLS test, we conclude that the series is $\mathrm{I}(0)$ and free of substantial structural change, given the low probability of obtaining such a rejection when structural change is present. ${ }^{14}$ Lopez, Murray, and Papell (2005) perform the DF-GLS unit root test on our 16 real exchange rates, using MAIC lag selection. They reject the unit root null at the 5\% level for 9 dollar denominated real exchange rates: Australia, Belgium, Finland, Germany, Italy, The Netherlands, Spain, Sweden, and the UK. We will focus only on these 9 real exchange rates.

We compute median-unbiased estimates of half-lives, and 95\% confidence intervals, for our remaining 9 stationary dollar denominated real exchange rates. As in our previous simulation experiment, the half-life is defined as the number of years required for a unit shock to dissipate by one-half, and is based directly on the impulse response function for each real exchange rate. In Table 3, we report half-life estimates from DFGLS regressions where the lag length has been chosen by the Modified Akaike information criterion (MAIC) of $\mathrm{Ng}$ and Perron (2001).

\footnotetext{
${ }^{14}$ We note that if the series exhibits mild structural change, where the size of the break is small relative to the innovation standard deviation, then it is possible to reject the unit root null.
} 
The point estimates of the half-lives in Table 3 are larger than what has been previously reported in the literature. The median point estimate is 7.46 years, with 5 of the 9 half-lives lying outside Rogoff's (1996) 3-5 year interval. This strengthens Murray and Papell's (2002) conclusion that the literature surveyed by Rogoff (1996) does not accurately represent the behavior of real exchange rates. Furthermore, the 95\% confidence intervals paint a much different picture of the persistence of deviations from PPP, vis-à-vis models with nominal rigidities. The median confidence interval for halflives of PPP deviations is $[2.86,21.24]$ years and, with the exception of the US/Finland real exchange rate, every lower bound is greater than 2 years.

An interesting feature of Table 3 is that the differences between $\alpha_{L S}$ and $\alpha_{M U}$ are quite small. This is due to the lack of deterministic terms in the auxiliary DF-GLS regression. Since the least squares half-life and the median-unbiased half-life are almost equal, one might be tempted to simply estimate the OLS half-life from the DF-GLS regression and forgo the median-bias correction. This is only a viable strategy if one is not concerned with the variability of the estimate. The practice in this literature is to look at confidence intervals for half-lives, not just point estimates. It is well known that constructing confidence intervals based on $\alpha_{L S}$ is problematic. The resulting confidence intervals do not have the correct coverage probabilities. ${ }^{15}$ However, the $95 \%$ medianunbiased confidence intervals have known coverage by construction. Thus, if one is interested in well behaved half-life confidence intervals, the fact that $\alpha_{L S}$ and $\alpha_{M U}$ are similar in the DF-GLS context seems largely unimportant.

We would like to know whether the larger point estimates and lower bounds of the confidence intervals that we report in Table 3 (compared with previous work) are solely caused by differences in techniques, or if differences in the data also play a role. To assess this, we also compute median-unbiased half-lives and 95\% confidence intervals

\footnotetext{
${ }^{15}$ Although we do not report them, we have constructed confidence intervals for $\alpha$, and thus the half-life, based on the OLS estimates. We used the delta-method, as well as both a parametric and a nonparametric bootstrap. In every case, these confidence intervals are shifted to the left of those reported in Table 3, and the coverage probabilities are much less than $95 \%$.
} 
based on ADF regressions with general-to specific (GS) lag selection. ${ }^{16}$ These are reported in Table 4.

The point estimates of the half-lives from ADF regressions in Table 4 are also larger than what has been previously reported in the literature. The median point estimate is 4.95 years, with 4 of the 9 half-lives lying outside Rogoff's (1996) 3-5 year interval. As with the DF-GLS regressions in Table 3, the 95\% confidence intervals paint a much different picture of the persistence of deviations from PPP than models with nominal rigidities. The median confidence interval for half-lives of PPP deviations is [2.92, 18.22] years and, again with the exception of the US/Finland real exchange rate, every lower bound is greater than 2 years.

What emerges from juxtaposing Tables 3 and 4 is the conclusion that our tighter confidence intervals are both technique and data driven. Applying Andrews and Chen's (1994) methodology to Taylor's (2002) longer data set results in much tighter intervals than Murray and Papell (2002) report using the same technique for the post-1973 floating period. It is also the case that our technique is partially responsible for the tightening of the intervals, although this may not be immediately apparent given that the median confidence interval in Table 4 is tighter than the median confidence interval in Table 3. This is purely an artifact of lag selection. If $k_{\text {MAIC }}=k_{G S}$, the half-lives are based on the DF-GLS regression are uniformly tighter than those based on the ADF regression. ${ }^{17}$ In practice, the selected lags will differ, and if $k_{M A I C} \neq k_{G S}$, DF-GLS intervals will not be uniformly tighter than ADF intervals, and vice-versa.

Both sets of confidence intervals are narrower than what currently exists in the literature, and the message from Table 3 and 4 is clear. Using the largest available dataset, we are unable to reconcile the predictions of exchange rate models with nominal rigidities with the behavior of real exchange rates. Therefore, while tighter confidence intervals translate to more information about the persistence of deviations from PPP, this increase in information moves us away from solving the PPP puzzle.

\footnotetext{
${ }^{16}$ General-to-Specific lag selection starts with a maximum lag, typically 8 in annual data, and does a sequence of hypothesis tests to determine the significance of the coefficient on the longest lagged first difference term. The procedure stops once a significant coefficient is found. See Hall (1994) and Ng and Perron (1995) for further discussion.
} 


\section{Conclusion}

Rogoff's (1996) "remarkable consensus" of 3-5 year half-lives of PPP deviations was based on studies using biased estimates that underestimate the magnitude of the PPP puzzle. Subsequent work using data for industrialized countries from the post-1973 flexible exchange rate period has obtained ambiguous conclusions. In Murray and Papell (2002) and Rossi (2005), the confidence intervals for half-lives are so wide that they are consistent with virtually anything. They range from a speed of reversion to PPP that is predicted by models with nominal rigidities (half-lives between 1 and 2 years) to the failure of PPP to hold in the long run (infinite half-lives).

In this paper, we investigate the purchasing power parity puzzle for Taylor's longhorizon data using more powerful techniques. We extend the median-unbiased estimation methodology developed by Andrews (1993) and Andrews and Chen (1994) to the DF-GLS regression of Elliott, Rothenberg, and Stock (1996), and report both point estimates and confidence intervals. Our simulations show that correcting for median-bias in the DF-GLS regression produces tighter confidence intervals than the more widely used ADF regression.

Rogoff (1996) argues that the combination of high short-run real exchange rate volatility and "glacial" speeds of mean reversion produce the PPP puzzle. Using the best available data and an improved estimator, we find half-lives of PPP deviations to be much larger than his $3-5$ year consensus. Another contribution of our work is to augment the information conveyed by point estimates with confidence intervals. In our earlier work, median-unbiased confidence intervals for PPP deviations were too wide to be informative. In this paper we see something much different. Similar to previous work, the upper bounds of the confidence intervals are quite high. In contrast to previous work, however, the lower bounds are also so high that we can rule out consistency with models based on nominal rigidities. While our quantitative results are very different from those reported by Rogoff, our conclusions are in some respects very similar. Using more precise techniques with a longer span of data moves us further away from solving the PPP puzzle.

\footnotetext{
${ }^{17}$ We do not report these results here, except for the US/UK real exchange rate, where the selected lags are equal.
} 


\section{References}

Abuaf, N. and P. Jorion, 1990, "Purchasing power parity in the long run," Journal of Finance 45, 157-174.

Andrews, D.W.K, 1993, "Exactly Median-Unbiased Estimation of First Order Autoregressive/Unit Root Models," Econometrica 61: 139-165.

Andrews, D.W.K., and H.-Y. Chen, 1994, "Approximately Median-Unbiased Estimation of Autoregressive Models," Journal of Business and Economic Statistics 12: 187-204.

Cheung, Y.-W., and K.S. Lai, 1994, "Mean Reversion in Real Exchange Rates," Economics Letters 46, 251-56.

Cheung, Y.-W. and K.S. Lai, 2000, “On the Purchasing Power Parity Puzzle," Journal of International Economics 52: 321-330.

Choi, C.Y., Mark, N., and D. Sul, 2005, "Unbiased Estimation of the Half-Life to PPP Convergence in Panel Data," forthcoming, Journal of Money, Credit and Banking.

Diebold, F., Husted, S., and Rush, M. 1991, "Real Exchange Rates Under the Gold Standard," Journal of Political Economy 99, 1252-1271.

Elliott G, and Stock, J.H., "Confidence Intervals for Autoregressive Coefficients Near One," Journal of Econometrics 103: 155-181.

Elliott, G. and Pesavento, E., 2006, “On the Failure of Purchasing Power Parity for Bilateral Exchange Rates after 1973," Journal of Money, Credit and Banking, 38: 1405-1430.

Elliott, G., Rothenberg, T., and Stock, J.H., 1996, "Efficient Tests for an Autoregressive Unit Root," Econometrica 64:813-836.

Engel, C.M., 2000, "Long-Run PPP May Not Hold After All," Journal of International Economics 51: 243-273.

Frankel, J., 1986, "International Capital Mobility and Crowding Out in the U.S. Economy: Imperfect Integration of Financial Markets or of Goods Markets?" in R. Hafer, ed., How Open is the U.S. Economy?, Lexington Books.

Glen, J.H., 1992, "Real Exchange Rates in the Short, Medium, and Long Run," Journal of International Economics 33, 147-66.

Hansen, B., 1999, "The Grid Bootstrap and the Autoregressive Model," The Review of Economics and Statistics 81, 594-607. 
Imbs, J., Mumtaz, H., Ravin, M. and H. Rey, 2005, "PPP Strikes Back: Aggregation and the Real Exchange Rate," Quarterly Journal of Economics 120, 1-43.

Inoue, A, and L. Kilian, 2002, "Bootstrapping Autoregressive Processes with Possible Unit Roots," Econometrica 70: 377-391.

Kilian, L., 1998, "Small-Sample Confidence Intervals for Impulse Response Functions," The Review of Economics and Statistics 80, 218-230.

Kilian, L., 1999, "Finite-Sample Properties of Percentile and Percentile- $t$ Bootstrap Confidence Intervals for Impulse Responses," The Review of Economics and Statistics 81, 652-660.

Kilian, L., and T. Zha, 2002, "Quantifying the Uncertainty about the Half-Life of Deviations from PPP," Journal of Applied Econometrics 17:107-125.

Lothian, J., and M. Taylor, 1996, "Real Exchange Rate Behavior: The Recent Float from the Perspective of the Past Two Centuries." Journal of Political Economy 104: 488-509.

Müller, U.K., and G. Elliott, 2003, "Tests for Unit Roots and the Initial Condition," Econometrica 71: 1269-1286.

Murray, C.J., and D.H. Papell, 2002, "The Purchasing Power Parity Persistence Paradigm," Journal of International Economics 56: 1-19.

Murray, C.J., and D.H. Papell, 2005, “Do Panels Help Solve the PPP Puzzle?," Journal of Business and Economics Statistics 23: 410-415.

Ng. S. and P. Perron, 2001 "Lag Length Selection and the Construction of Unit Root Tests with Good Size and Power." Econometrica 69: 1519-1554.

Papell, D.H, and R. Prodan, 2007, "Restricted Structural Change and the Unit Root Hypothesis," Economic Inquiry: 45: 834-853.

Perron, P., 1989, "The Great Crash, the Oil Price Shock, and the Unit Root Hypothesis," Econometrica 57, 1361-1401.

Rogoff, K., 1996, “The Purchasing Power Parity Puzzle," Journal of Economic Literature 34: 647-668.

Rossi, B., 2005, "Confidence Intervals for Half-Life Deviations from Purchasing Power Parity," Journal of Business and Economic Statistics 23: 432-442. 
Taylor, A.M., 2001, "Potential Pitfalls for the Purchasing-Power-Parity Puzzle? Sampling and Specification Biases in Mean-Reversion Tests of the Law of One Price," Econometrica 69, 473-498.

Taylor, A.M., 2002, “A Century of Purchasing Power Parity," The Review of Economics and Statistics 84, 139-150. 
Table 1. Exactly Median-Unbiased Estimators

DF-GLS Exactly Median-Unbiased Estimator

\begin{tabular}{|c|c|c|c|c|c|c|c|c|c|c|c|c|}
\hline \multirow[b]{2}{*}{$\alpha /$ Quantile } & \multicolumn{3}{|c|}{$\mathrm{T}+1=40$} & \multicolumn{3}{|c|}{$\mathrm{T}+1=50$} & \multicolumn{3}{|c|}{$\mathrm{T}+1=60$} & \multicolumn{3}{|c|}{$\mathrm{T}+1=70$} \\
\hline & 0.05 & 0.50 & 0.95 & 0.05 & 0.50 & 0.95 & 0.05 & 0.50 & 0.95 & 0.05 & 0.50 & 0.95 \\
\hline 1 & 0.737 & 0.930 & 1.000 & 0.797 & 0.950 & 1.000 & 0.834 & 0.962 & 1.000 & 0.862 & 0.970 & 1.000 \\
\hline 0.99 & 0.727 & 0.918 & 1.000 & 0.781 & 0.938 & 1.000 & 0.820 & 0.949 & 1.000 & 0.845 & 0.957 & 1.000 \\
\hline 0.97 & 0.696 & 0.895 & 0.982 & 0.755 & 0.915 & 0.984 & 0.793 & 0.927 & 0.984 & 0.817 & 0.936 & 0.985 \\
\hline 0.93 & 0.646 & 0.856 & 0.956 & 0.702 & 0.876 & 0.959 & 0.738 & 0.887 & 0.959 & 0.766 & 0.896 & 0.960 \\
\hline 0.9 & 0.612 & 0.827 & 0.938 & 0.665 & 0.847 & 0.941 & 0.702 & 0.858 & 0.941 & 0.727 & 0.866 & 0.941 \\
\hline 0.85 & 0.553 & 0.782 & 0.908 & 0.607 & 0.799 & 0.909 & 0.643 & 0.812 & 0.909 & 0.665 & 0.818 & 0.908 \\
\hline 0.8 & 0.501 & 0.737 & 0.877 & 0.551 & 0.752 & 0.876 & 0.583 & 0.762 & 0.874 & 0.610 & 0.771 & 0.872 \\
\hline
\end{tabular}

Andrews (1993) OLS Exactly Median-Unbiased Estimator

\begin{tabular}{|c|c|c|c|c|c|c|c|c|c|c|c|c|}
\hline \multirow[b]{2}{*}{$\alpha /$ Quantile } & \multicolumn{3}{|c|}{$\mathrm{T}+1=40$} & \multicolumn{3}{|c|}{$\mathrm{T}+1=50$} & \multicolumn{3}{|c|}{$\mathrm{T}+1=60$} & \multicolumn{3}{|c|}{$\mathrm{T}+1=70$} \\
\hline & 0.05 & 0.50 & 0.95 & 0.05 & 0.50 & 0.95 & 0.05 & 0.50 & 0.95 & 0.05 & 0.50 & 0.95 \\
\hline 1 & 0.674 & 0.893 & 0.999 & 0.735 & 0.914 & 0.999 & 0.777 & 0.928 & 0.999 & 0.807 & 0.938 & 0.999 \\
\hline 0.99 & 0.666 & 0.886 & 0.994 & 0.727 & 0.907 & 0.994 & 0.769 & 0.921 & 0.994 & 0.799 & 0.931 & 0.994 \\
\hline 0.97 & 0.649 & 0.872 & 0.983 & 0.706 & 0.893 & 0.982 & 0.750 & 0.906 & 0.982 & 0.780 & 0.916 & 0.982 \\
\hline 0.93 & 0.612 & 0.841 & 0.958 & 0.669 & 0.860 & 0.957 & 0.709 & 0.873 & 0.957 & 0.737 & 0.882 & 0.957 \\
\hline 0.9 & 0.582 & 0.816 & 0.939 & 0.638 & 0.834 & 0.938 & 0.676 & 0.846 & 0.938 & 0.704 & 0.854 & 0.937 \\
\hline 0.85 & 0.532 & 0.772 & 0.908 & 0.585 & 0.789 & 0.906 & 0.622 & 0.800 & 0.905 & 0.648 & 0.807 & 0.903 \\
\hline 0.8 & 0.480 & 0.727 & 0.875 & 0.532 & 0.743 & 0.872 & 0.567 & 0.753 & 0.870 & 0.593 & 0.760 & 0.867 \\
\hline
\end{tabular}


Table 1. Exactly Median-Unbiased Estimators, Continued

DF-GLS Exactly Median-unbiased Estimator

\begin{tabular}{|c|c|c|c|c|c|c|c|c|c|c|c|c|}
\hline \multirow[b]{2}{*}{$\alpha /$ Quantile } & \multicolumn{3}{|c|}{$\mathrm{T}+1=80$} & \multicolumn{3}{|c|}{$\mathrm{T}+1=90$} & \multicolumn{3}{|c|}{$\mathrm{T}+1=100$} & \multicolumn{3}{|c|}{$\mathrm{T}+1=125$} \\
\hline & 0.05 & 0.50 & 0.95 & 0.05 & 0.50 & 0.95 & 0.05 & 0.50 & 0.95 & 0.05 & 0.50 & 0.95 \\
\hline 1 & 0.879 & 0.975 & 1.000 & 0.894 & 0.979 & 1.000 & 0.906 & 0.982 & 1.000 & 0.927 & 0.987 & 1.000 \\
\hline 0.99 & 0.864 & 0.963 & 1.000 & 0.879 & 0.967 & 1.000 & 0.891 & 0.970 & 1.000 & 0.912 & 0.976 & 1.000 \\
\hline 0.97 & 0.837 & 0.942 & 0.985 & 0.852 & 0.946 & 0.985 & 0.862 & 0.949 & 0.985 & 0.884 & 0.955 & 0.985 \\
\hline 0.93 & 0.785 & 0.902 & 0.960 & 0.799 & 0.906 & 0.960 & 0.809 & 0.909 & 0.960 & 0.832 & 0.915 & 0.960 \\
\hline 0.9 & 0.747 & 0.872 & 0.941 & 0.761 & 0.877 & 0.940 & 0.773 & 0.879 & 0.939 & 0.793 & 0.885 & 0.938 \\
\hline 0.85 & 0.684 & 0.824 & 0.907 & 0.699 & 0.827 & 0.905 & 0.713 & 0.831 & 0.905 & 0.735 & 0.835 & 0.901 \\
\hline 0.8 & 0.627 & 0.774 & 0.870 & 0.641 & 0.779 & 0.868 & 0.654 & 0.782 & 0.867 & 0.678 & 0.787 & 0.863 \\
\hline
\end{tabular}

Andrews (1993) OLS Exactly Median-Unbiased Estimator

\begin{tabular}{|c|c|c|c|c|c|c|c|c|c|c|c|c|}
\hline \multirow[b]{2}{*}{$\alpha /$ Quantile } & \multicolumn{3}{|c|}{$\mathrm{T}+1=80$} & \multicolumn{3}{|c|}{$\mathrm{T}+1=90$} & \multicolumn{3}{|c|}{$\mathrm{T}+1=100$} & \multicolumn{3}{|c|}{$\mathrm{T}+1=125$} \\
\hline & 0.05 & 0.50 & 0.95 & 0.05 & 0.50 & 0.95 & 0.05 & 0.50 & 0.95 & 0.05 & 0.50 & 0.95 \\
\hline 1 & 0.831 & 0.946 & 0.999 & 0.849 & 0.952 & 0.999 & 0.863 & 0.957 & 0.999 & 0.890 & 0.965 & 0.999 \\
\hline 0.99 & 0.822 & 0.939 & 0.994 & 0.840 & 0.945 & 0.994 & 0.854 & 0.950 & 0.994 & 0.881 & 0.958 & 0.994 \\
\hline 0.97 & 0.802 & 0.923 & 0.982 & 0.820 & 0.929 & 0.981 & 0.834 & 0.933 & 0.981 & 0.859 & 0.941 & 0.981 \\
\hline 0.93 & 0.758 & 0.888 & 0.956 & 0.775 & 0.893 & 0.956 & 0.788 & 0.897 & 0.956 & 0.813 & 0.904 & 0.955 \\
\hline 0.9 & 0.724 & 0.861 & 0.937 & 0.741 & 0.865 & 0.936 & 0.754 & 0.869 & 0.936 & 0.778 & 0.876 & 0.934 \\
\hline 0.85 & 0.668 & 0.813 & 0.902 & 0.684 & 0.818 & 0.901 & 0.697 & 0.821 & 0.900 & 0.721 & 0.827 & 0.897 \\
\hline 0.8 & 0.613 & 0.765 & 0.865 & 0.628 & 0.769 & 0.863 & 0.641 & 0.773 & 0.862 & 0.664 & 0.778 & 0.858 \\
\hline
\end{tabular}


Table 1. Exactly Median-Unbiased Estimators, Continued DF-GLS Exactly Median-Unbiased Estimator

\begin{tabular}{cccccccc}
\hline & \multicolumn{3}{c}{$T+1=150$} & & \multicolumn{3}{c}{$T+1=200$} \\
\cline { 2 - 4 } \cline { 7 - 8 }$\alpha /$ Quantile & 0.05 & 0.50 & 0.95 & & 0.05 & 0.50 & 0.95 \\
\hline 1 & 0.941 & 0.990 & 1.000 & & 0.956 & 0.993 & 1.000 \\
0.99 & 0.924 & 0.979 & 0.999 & & 0.941 & 0.982 & 0.998 \\
0.97 & 0.896 & 0.958 & 0.985 & & 0.913 & 0.962 & 0.985 \\
0.93 & 0.845 & 0.918 & 0.959 & & 0.861 & 0.922 & 0.957 \\
0.9 & 0.808 & 0.888 & 0.937 & & 0.825 & 0.892 & 0.935 \\
0.85 & 0.749 & 0.839 & 0.899 & & 0.767 & 0.843 & 0.895 \\
0.8 & 0.692 & 0.789 & 0.860 & & 0.710 & 0.793 & 0.854 \\
\hline
\end{tabular}

Andrews (1993) OLS Exactly Median-Unbiased Estimator

\begin{tabular}{ccccccccc}
\hline & \multicolumn{3}{c}{$\mathrm{T}+1=150$} & & \multicolumn{3}{c}{$\mathrm{T}+1=200$} \\
\cline { 2 - 4 } \cline { 7 - 9 }$\alpha /$ Quantile & 0.05 & 0.50 & 0.95 & & 0.05 & 0.50 & 0.95 \\
\hline 1 & 0.908 & 0.971 & 0.999 & & 0.931 & 0.978 & 0.999 \\
0.99 & 0.898 & 0.964 & 0.994 & & 0.921 & 0.971 & 0.994 \\
0.97 & 0.876 & 0.947 & 0.981 & & 0.898 & 0.953 & 0.981 \\
0.93 & 0.829 & 0.909 & 0.955 & & 0.850 & 0.915 & 0.953 \\
0.9 & 0.794 & 0.880 & 0.933 & & 0.815 & 0.885 & 0.931 \\
0.85 & 0.737 & 0.831 & 0.895 & & 0.758 & 0.836 & 0.891 \\
0.8 & 0.681 & 0.782 & 0.855 & & 0.702 & 0.787 & 0.850 \\
\hline
\end{tabular}


Table 2. Relative Performance of Approximately Median-Unbiased Half-Life Estimates Based on DF-GLS and ADF Regressions

\begin{tabular}{|c|c|c|c|c|c|}
\hline & \multirow{2}{*}{$\begin{array}{c}\text { True } \\
\text { Half-Life }\end{array}$} & \multicolumn{4}{|c|}{ Median-Unbiased Estimates } \\
\hline & & DF-GLS & $95 \% \mathrm{CI}$ & $\mathrm{ADF}$ & $95 \% \mathrm{CI}$ \\
\hline \multicolumn{6}{|l|}{$\alpha=1$} \\
\hline$\phi_{1}=1.25, \phi_{2}=-0.25$ & $\infty$ & 73.45 & {$[12.10, \infty)$} & $\infty$ & {$[9.11, \infty)$} \\
\hline$\phi_{1}=1.50, \phi_{2}=-0.50$ & $\infty$ & $\infty$ & {$[15.23, \infty)$} & $\infty$ & {$[11.64, \infty)$} \\
\hline$\phi_{1}=0.80, \phi_{2}=0.20$ & $\infty$ & 62.89 & {$[5.32, \infty)$} & $\infty$ & {$[3.97, \infty)$} \\
\hline$\phi_{1}=0.60, \phi_{2}=0.40$ & $\infty$ & 52.91 & {$[4.03, \infty)$} & $\infty$ & {$[2.74, \infty)$} \\
\hline \multicolumn{6}{|l|}{$\alpha=0.95$} \\
\hline$\phi_{1}=1.25, \phi_{2}=-0.30$ & 14.63 & 12.21 & {$[5.40,36.64]$} & 14.64 & {$[5.28, \infty)$} \\
\hline$\phi_{1}=1.50, \phi_{2}=-0.55$ & 13.66 & 12.77 & {$[6.90,34.44]$} & 13.49 & {$[6.87,68.34]$} \\
\hline$\phi_{1}=0.80, \phi_{2}=0.15$ & 12.26 & 10.32 & {$[3.22,60.02]$} & 12.05 & {$[2.95, \infty)$} \\
\hline$\phi_{1}=0.60, \phi_{2}=0.35$ & 9.99 & 8.22 & {$[2.49,51.97]$} & 10.51 & {$[2.24, \infty)$} \\
\hline \multicolumn{6}{|l|}{$\alpha=0.90$} \\
\hline$\phi_{1}=1.25, \phi_{2}=-0.35$ & 7.41 & 6.79 & {$[4.12,14.50]$} & 7.37 & {$[4.01,18.28]$} \\
\hline$\phi_{1}=1.55, \phi_{2}=-0.85$ & 6.62 & 6.29 & {$[3.83,11.82]$} & 6.70 & {$[3.74,17.61]$} \\
\hline$\phi_{3}=0.20$ & & & & & \\
\hline$\phi_{1}=0.60, \phi_{2}=0.30$ & 4.98 & 4.49 & {$[2.06,11.77]$} & 4.94 & {$[2.01,58.18]$} \\
\hline \multicolumn{6}{|l|}{$\alpha=0.85$} \\
\hline$\phi_{1}=1.25, \phi_{2}=-0.40$ & 5.17 & 5.02 & {$[3.34,8.24]$} & 6.11 & {$[3.35,9.14]$} \\
\hline $\begin{array}{l}\phi_{1}=1.55, \phi_{2}=-0.85, \\
\phi_{3}=0.15\end{array}$ & 4.92 & 4.86 & {$[3.61,7.35]$} & 4.93 & {$[3.64,8.49]$} \\
\hline$\phi_{1}=0.60, \phi_{2}=0.25$ & 3.30 & 3.02 & {$[0.86,7.50]$} & 3.14 & {$[0.85,10.96]$} \\
\hline
\end{tabular}


Table 3. Median-Unbiased Half-Lives in DF-GLS Regressions

\begin{tabular}{cccccccc}
\hline Country & Sample & $k_{\text {MAIC }}$ & $\alpha_{L S}$ & $\alpha_{M U}$ & $95 \%$ CI & $H L_{M U}$ & $95 \%$ CI \\
\hline Australia & $1870-1998$ & 0 & 0.913 & 0.928 & {$[0.853,1.0]$} & 9.28 & {$[4.36, \infty)$} \\
Belgium & $1880-1998$ & 3 & 0.872 & 0.879 & {$[0.771,0.975]$} & 3.73 & {$[2.37,12.67]$} \\
Finland & $1881-1998$ & 0 & 0.704 & 0.716 & {$[0.580,0.848]$} & 2.07 & {$[1.27,4.02]$} \\
Germany & $1880-1998$ & 2 & 0.943 & 0.948 & {$[0.889,1.0]$} & 14.17 & {$[5.14,72.86]$} \\
Italy & $1880-1998$ & 0 & 0.825 & 0.839 & {$[0.734,0.946]$} & 3.95 & {$[2.24,12.49]$} \\
Netherlands & $1870-1998$ & 2 & 0.927 & 0.934 & {$[0.877,1.0]$} & 10.26 & {$[4.14,34.29]$} \\
Spain & $1880-1998$ & 3 & 0.924 & 0.933 & {$[0.850,1.0]$} & 9.36 & {$[3.03,35.07]$} \\
Sweden & $1880-1998$ & 2 & 0.905 & 0.911 & {$[0.829,0.989]$} & 7.46 & {$[2.76,21.24]$} \\
UK & $1870-1998$ & 4 & 0.886 & 0.894 & {$[0.783,0.987]$} & 3.91 & {$[2.86,12.55]$} \\
\hline
\end{tabular}

Table 4. Median-Unbiased Half-Lives in ADF Regressions

\begin{tabular}{cccccccc}
\hline Country & Sample & $k_{G S}$ & $\alpha_{L S}$ & $\alpha_{M U}$ & $95 \%$ CI & $H L_{M U}$ & $95 \%$ CI \\
\hline Australia & $1870-1998$ & 1 & 0.897 & 0.921 & {$[0.838,1.0]$} & 8.81 & {$[3.86,36.00]$} \\
Belgium & $1880-1998$ & 1 & 0.780 & 0.797 & {$[0.698,0.902]$} & 3.78 & {$[2.44,6.67]$} \\
Finland & $1881-1998$ & 1 & 0.584 & 0.602 & {$[0.457,0.735]$} & 2.11 & {$[1.57,2.87]$} \\
Germany & $1880-1998$ & 1 & 0.910 & 0.928 & {$[0.862,1.0]$} & 10.44 & {$[5.00,72.00]$} \\
Italy & $1880-1998$ & 2 & 0.753 & 0.766 & {$[0.667,0.859]$} & 3.76 & {$[2.42,5.69]$} \\
Netherlands & $1870-1998$ & 1 & 0.904 & 0.923 & {$[0.849,1.0]$} & 9.13 & {$[4.52,24.42]$} \\
Spain & $1880-1998$ & 1 & 0.875 & 0.893 & {$[0.816,0.978]$} & 6.70 & {$[3.54,18.22]$} \\
Sweden & $1880-1998$ & 1 & 0.829 & 0.847 & {$[0.749,0.947]$} & 4.95 & {$[2.89,10.42]$} \\
UK & $1870-1998$ & 4 & 0.852 & 0.885 & {$[0.757,1.0]$} & 4.02 & {$[2.92,50.94]$} \\
\hline
\end{tabular}

